\title{
Apresentação
}

\section{Riqueza: totem e tabu}

ANTONIO DAVID CATTANI*

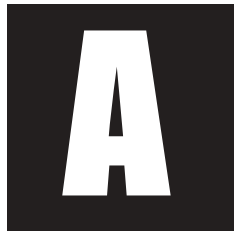

s desigualdades socioeconômicas no Brasil são analisadas, na grande maioria das vezes, considerando-se apenas os pobres e os miseráveis. Sobre eles, proliferam estudos acerca das condições de vida, dos comportamentos políticos, das estratégias de sobrevivência etc. A mesma pletora de dados e análises não existe a respeito do topo da estrutura social, aquele constituído por uma minoria que, embora não ultrapasse 1\% da população, detém parte substantiva da riqueza nacional, tendo, conseqüentemente, poder de decisão sobre aspectos fundamentais da vida econômica, política e cultural do País.

Excetuando-se o que se sabe por meio dos estudos a propósito da representação política e sobre o desempenho empresarial, as classes abastadas permanecem incógnitas e mitificadas. Por um lado, os detentores de grandes fortunas surgem como seres extraordinários, talentosos, empreendedores, dinâmicos, elites constituindo objeto de veneração. A legitimidade social é notória e dificulta uma análise mais pormenorizada que leve à identificação das estratégias de poder e de dominação. Por outro lado, os ricos constituem um segmento tabu, cujo acesso, por hipocrisia ou temor, é impedido ou evitado. A sacralização do sigilo bancário, o medo de seqües-

* Professor Titular de Sociologia do Programa de Pós-Graduação em Sociologia - UFRGS e pesquisador CNPq. Brasil 
tros e extorsões ou o lado escuso de muitas fortunas fazem com que a composição social e as dimensões substantivas da riqueza permaneçam ao abrigo dos olhares críticos do conjunto da sociedade.

É um grande desafio para a Sociologia superar falsos problemas deontológicos no estudo dos ricos e o equivocado entendimento de que a pobreza é um problema e que a riqueza não o é. No país que bate recordes expressivos de concentração de renda, é importante desmistificar totens e tabus constituídos em torno do vértice da pirâmide social, revelando que as classes abastadas não são auto-referentes nem tampouco auto-suficientes, mas encarnações de relações de poder e de exploração. Na contracorrente da ideologia neoliberal, é necessário reafirmar a importância do estudo sobre a estrutura social configurada em termos de classes com profundas diferenças na distribuição de poderes e direitos, na posse e utilização de recursos produtivos e na fruição dos bens e serviços resultantes do esforço coletivo. A estratificação social não é equivalente a uma espécie de topologia natural, simples sobreposição de camadas diferenciadas, mas estanques. A lógica intrínseca ao sistema capitalista configura relações de poder, de exploração e de dominação que se traduzem em desigualdades permanentes e, dependendo da correlação de forças, em desigualdades crescentes.

O dossiê apresentando neste número da revista Sociologias é composto por uma série de artigos que buscam preencher o déficit explicativo existente sobre a estrutura social e apresentam perspectivas teóricas e empíricas pretendendo contribuir para melhor se analisarem as dimensões essenciais da relação entre riqueza e desigualdades.

A abertura do dossiê é feita com um artigo inédito de Michel Pinçon e de Monique Pinçon-Charlot. Sociólogos de projeção internacional, eles são autores de aprofundadas e consistentes pesquisas sobre a alta burguesia francesa (é importante sinalizar que a França é o país que possui os mais altos índices de concentração de renda entre as 10 maiores potências eco- 
nômicas mundiais). Seus estudos empíricos dão seqüência às obras clássicas de Pierre Bourdieu sobre os processos de dominação e de reprodução das classes dominantes. É provável que as condições históricas e materiais de existência da burguesia francesa dificilmente sirvam de parâmetro para se estudar a situação brasileira. Entretanto, o referencial teórico, os conceitos e, sobretudo, as observações de caráter metodológico desses autores são aportes imprescindíveis para a análise das relações de classe na atualidade. O grande interesse desse artigo reside no fato de apresentar com clareza que os obstáculos metodológicos que impedem a análise das classes sociais são provenientes, muitas vezes, dos limites pessoais do pesquisador. Este pode dispor de teorias rigorosas e pertinentes, mas sua hexis (conceito mais complexo e abrangente que habitus) impede-o de avançar no tocante ao conhecimento de indivíduos importantes que se valem "naturalmente" do efeito de poder. O mal-estar deontológico sentido pelos pesquisadores trabalhando com informações provenientes dos muito ricos não se manifesta quando o objeto são os pobres. A isso, se somam preconceitos provenientes de inexplicáveis equívocos, tais como "estudar ricos é defender a causa dos ricos" ou "estudar ricos é ser elitista".

Sonia Alvarez Leguizamón retoma os argumentos que norteiam um dos mais importantes livros sobre a desigualdade na América Latina (Alvarez Leguizamón, 2005). A pobreza, longe de ser um resquício histórico, é continuamente recriada por processos econômicos e políticos, sendo de suma importância " ubicar en um lugar de alta visibilidad a los agentes y estructuras que contribuyen a producir, mantener y reproducir la pobreza" (Cimadamore, 2005, p.14). Apresentando dados recentes, Alvarez Leguizamón analisa alguns dos significados sociológicos e políticos da concentração de renda na América Latina. A imensa brecha social já existente alargou-se devido à reestruturação neoliberal e à globalização. Em poucas palavras, os pobres ficaram mais pobres e os ricos, ainda mais ricos. Além disso, milionários e 
bilionários latino-americanos desenvolvem uma nova estratégia de poder configurada na filantropia, que lhes assegura legitimidade social e preservação de privilégios numa sociedade cada vez mais desigual.

Referindo-me especificamente ao caso brasileiro, meu artigo insiste na necessidade de se recuperar a dimensão relacional entre o "pólo riqueza" e o "pólo pobreza", destacando, para tanto, a desmedida que caracteriza a brecha social. Para uma melhor avaliação do significado da concentração de quase 50\% da renda nacional nas mãos de 1\% da população, é apresentado o conceito de "riqueza substantiva", entendida como a disponibilidade de recursos concretos, bens essenciais e propriedades em volume considerável possibilitando o exercício ampliado do poder sobre a sociedade e modificando, inclusive, a disputa intercapitalista. O artigo refere-se também ao processo de personificação da riqueza: recursos importantes saem da esfera produtiva e são destinados a um mercado restrito de alto luxo, com inéditos significados econômicos e sociais. Apesar das evidências empíricas do aumento da desigualdade socioeconômica, restrições materiais e insuficiências teóricas, além de problemas indicados também no artigo de Michel Pinçon e Monique Pinçon-Charlot, dificultam o acesso do pesquisador e traduzem um importante déficit explicativo sobre a estrutura social.

As instituições financeiras destacam-se como os segmentos do capital hegemônico no Brasil, adaptando-se aos diversos contextos econômicos e políticos de maneira a assegurar expressiva lucratividade. Partindo desta constatação, Ary César Minella analisa elementos do poder das 10 mais importantes instituições financeiras privadas. Para além da sua posição de agentes intermediários no campo das finanças, os bancos configuram-se como grupos econômicos e como unidades de articulação política em conexão direta com o Estado. O trânsito privado-público evidencia-se, por exemplo, na ocupação de cargos decisivos no Banco Central. Financiando campanhas eleitorais e organizações político-ideológicas, os bancos cons- 
tituem-se não apenas como lócus da acumulação e da concentração da riqueza, mas também como poder sociopolítico efetivo sobre a sociedade.

A partir de uma grande pesquisa realizada em 2000 cujo objetivo era captar atitudes e opiniões sobre valores de igualdade e justiça distributiva, além de percepções sobre a estratificação social, Celi Scalon analisa as diferenças existentes entre a "elite", definida como os 10\% mais ricos, e o restante da população. As principais questões visavam apreender se os brasileiros viam o Brasil como um país desigual e, em caso positivo, onde localizavam as desigualdades e quais seriam os principais problemas sociais que afligiam a população. Os resultados confirmaram a existência de uma cultura compartilhada que explica a legitimação das desigualdades e a convivência com seus níveis tão elevados e profundos. Mesmo assim, tanto elite como povo reconheceram viver numa sociedade desigual, desejando uma estrutura "com desenho mais humano". Scalon destaca o resultado da enquête cujo significado sociológico e político é o mais preocupante: a atribuição de responsabilidade ao Estado na busca de soluções e, variação da mesma percepção, a descrença na capacidade de a própria sociedade combater as injustiças.

O artigo de Ricardo Costa de Oliveira aborda a reprodução centenária de redes políticas e de poder existentes no estado do Paraná. A estrutura de poder materializa-se em relações familiares e pessoais, constituindo uma intrincada rede política que assegura privilégios por meio da inserção nas várias instâncias do aparelho de Estado. Nepotismo, clientelismo, corrupção e adesismo ao poder central são estratégias habituais para assegurar a reprodução das classes abastadas. Costa de Oliveira procede à genealogia de famílias ilustres, desmistificando a visão que toma o estado do Paraná como lócus de um capitalismo racional, transparente e marcado pelo empreendedorismo autenticamente liberal.

O último artigo apresenta dimensões específicas da construção das classes por meio da escolarização dos jovens provenientes dos segmentos 
mais abastados considerando os resultados das análises realizadas na última década e, em especial, aqueles que destacam a visão instrumental e utilitarista dos ricos com relação à escola secundária. Existem indicações de, que, no Brasil, parece haver um padrão rebaixado da formação escolar de frações das classes dominantes, como se seu poder estivesse tão consolidado que elas pudessem abrir mão de recursos simbólicos propiciados pela educação formal.

Sob enfoques diferenciados e com referenciais teóricos e empíricos plurais, os artigos que compõem este dossiê possuem uma unidade: pôr em evidência dimensões do "pólo riqueza" ocultadas pela ideologia e pelos efeitos do poder, mas, também por certas insuficiências das Ciências Sociais. Objeto de raros estudos sociológicos, as classes abastadas desenvolvem sutis estratagemas no que concerne à visibilidade dos seus papéis na sociedade. Ora se expondo como empreendedores audazes, como lideranças clarividentes ou como beneméritos protetores dos mais pobres, ora se escondendo para assegurar a tranqüila fruição da riqueza adquirida nem sempre de forma legítima, as classes abastadas valem-se de todos os expedientes legais e ilegais para assegurar sua reprodução. Contam, para tanto, com a impunidade, com as relações privilegiadas no aparelho de Estado, com a cumplicidade dos grandes meios de comunicação e, por vezes, com a leniência da Academia.

Constituem desafios para a Sociologia desmitificar e desmistificar totens e tabus e analisar cientificamente como se constituem e se relacionam as classes abastadas, que, de forma alguma, são auto-suficientes e auto-referentes. O estudo das dimensões relacionais entre os diferentes segmentos da sociedade, das formas de apropriação da riqueza social e das múltiplas estratégias de dominação é tão importante quanto o estudo das resistências e da criação histórica levadas pelos movimentos sociais. 
Sociologias, Porto Alegre, ano 9, no 18, jul./dez. 2007, p. 14-21

\section{Referências}

ALVAREZ LEGUIZAMON, Sonia (Org.). Trabajo y producción de la pobreza en Latinoamérica y el Caribe. Buenos Aires: Clacso Libros, 2005.

CIMADAMORE, Alberto. Prólogo. In: ALVAREZ LEGUIZAMÓN, Sonia (Org.). Trabajo y producción de la pobreza en Latinoamérica y el Caribe. Buenos Aires: Clacso Libros, 2005. 


\section{Resumo}

As desigualdades socioeconômicas são analisadas considerando-se, habitualmente, apenas o "pólo pobreza" sendo raros os estudos sociológicos sobre as classes abastadas. As dificuldades para as Ciências Sociais se devem a aspectos materiais (falta de acesso aos dados essenciais) mas, também, a equivocados problemas deontológicos. A Apresentação resume as contribuições específicas de cada artigo que compõem o dossiê "Riqueza e Desigualdades" destacando que, apesar da diversidade das contribuições e dos referenciais teóricos empregados, eles possuem uma unidade: pôr em evidência dimensões do "pólo riqueza" ocultadas pela ideologia e pelos efeitos de poder. Um dos desafios para a Sociologia é de desmistificar e desmitificar totens e tabus criados em torno da existência material e social das classes ricas que não são auto-referentes e nem auto-suficientes mas que estabelecem relações específicas de exploração e de dominação sobre a estrutura social.

Palavras-chave: teoria social, classes sociais, desigualdades.

Recebido: 23/05/07

Aceite Final: 10/06/07 